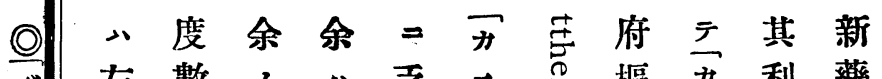

犬左數三八元空樞开利藥

ル, 總た获三上氏密大害必

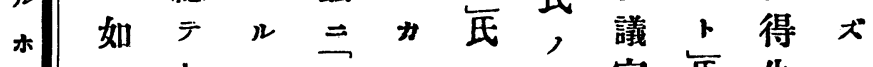

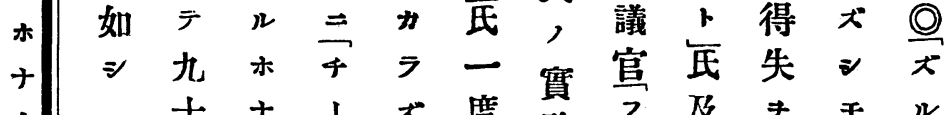

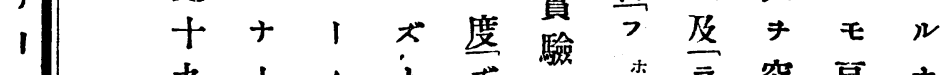

"2

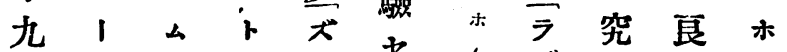

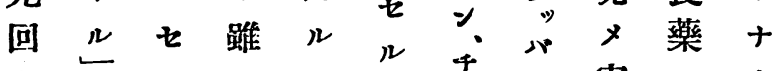

十

眠

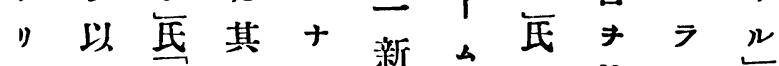

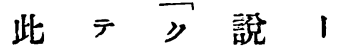

說七, 捨 だ篗

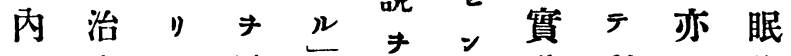

迥 二療 $=$ 增 7 得 或驗利必作

人三1補賞多,

加

メタキシ用ル可諸取シ,

健ル 其

康患於藥

体者テ性ヤ层報キ効

二小執 ま之左 ₹告, +

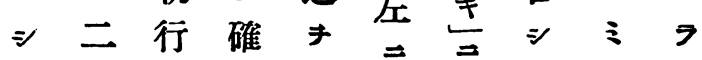

テ十シ定試之於 編 ゙

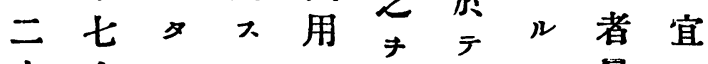

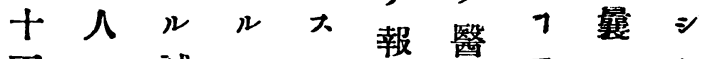

五二試入ル告學》= 》

人 $三$ 驗敢, 七卒り。本之

、テ, テ輩と業シ會き

不之成妨漸卜生方報許

眠 =綪 ゙ク欲全令告多

症服 $\neq+$ 多欲第，

$+$

二藥 報 $\neq$ 》

罹 ゼが隨

V $=テ$ 如 $テ$

其 メ $\quad$ 實

原

故 驗

因

= 說

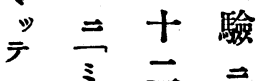

茫 シ 號 徵

禾

完 
呈 即 犬゙

フ千ッ十二文者常完二シか

最木八五每 $心$ 六全十卜用訮性血

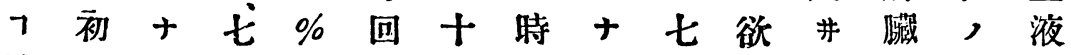

是, 小五十服一間ル人シ不循

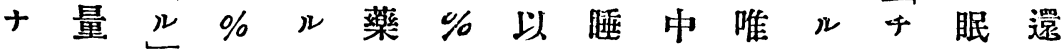

》無ノ副

余効 程 作以度 $y= \pm$ 人常口二害

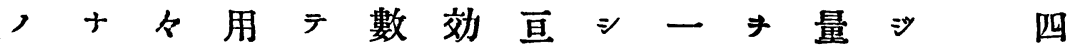

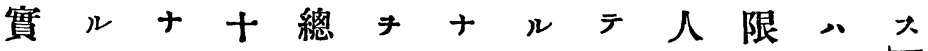

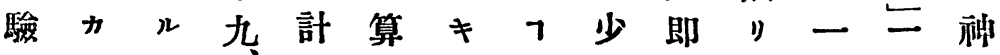

中或作入催除者ア》チ經

此 $\therefore$ 用八眠 $三$ 二 $モ$ 五至

，作 $夫 \%$, 更十七六十无二冰二

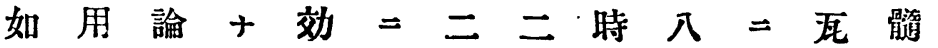

キ充 ボリ ま 之 $\%$ 間 $\%$ 至

7 分 ル

奏 副回持 $\Rightarrow ル レ ー$ 慢

二 + =

三 ラ 當

七改作入續在, 氏

性

问 ザ り

シ算用其 $シ テ$ 量脉

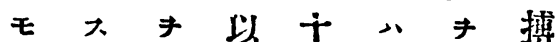

= ガ 頗.

ル 發

及础ル

二 = 泩

$\therefore$ \# $=$ +

下 催 用

用

酒脊 風

リ次意

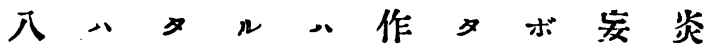

今回7

其 $\Rightarrow$ 次

一與 キ

例 貸

十 完

一全者アトキフ影

客髓 四

二作 二

五用二タ全セり ま

惡 進 染

$\%$ 七 $\%$ $\%$ 其 脉 性行病

F $>$ 値

卜十 = 其 $上$ 就成波負性三

學 ル

ゲ 時 ル

ン 强 —

$=$ 作 點

一用?

+ 二 相

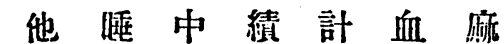

》\% 當

不 眠

四左

* 一瘰

陰不七完

性完り全催九如 テ

狂 全

結全ナシ $\%$ シ 確

患 ま り

果九

ル通

定

触 


\section{五○二 號三十五第告報會究㸴事醫、堂天順}

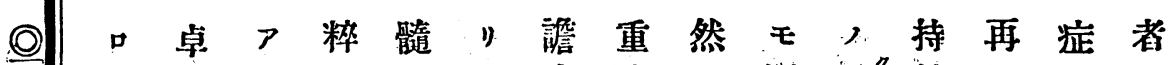
可 1 効”, 勞き安症上染重”長 E゙, 十 $x \Rightarrow \neq$ 余神等肺等， E

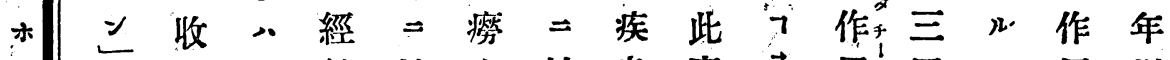

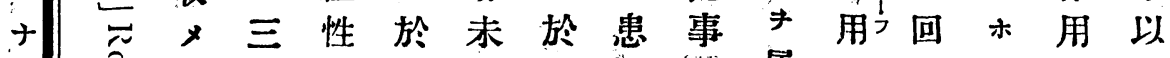

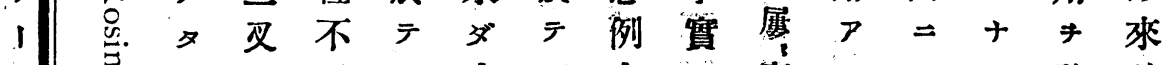

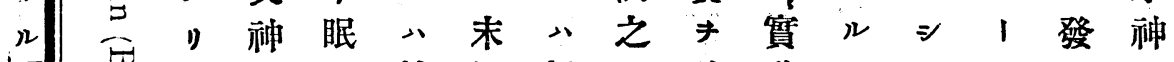
催

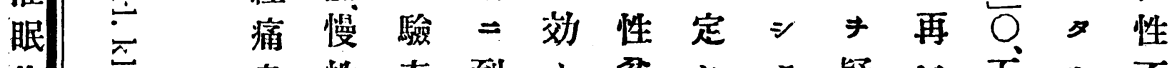
作患性充到十䀜七》疑七五儿不 用若奉分

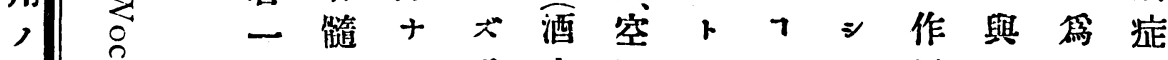
迎 名膜 $ラ$ 咳客洞 $大 又 \rtimes$ 用 $こ=$ 加

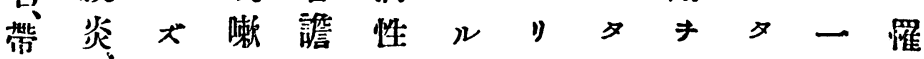
狀進之及妄肺

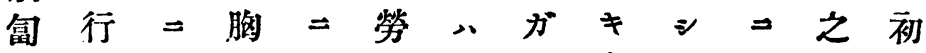
行性反痛於二余盖余其完 ガ 疹麻 ”㿉心几儿テ賽彼天昔十用ル

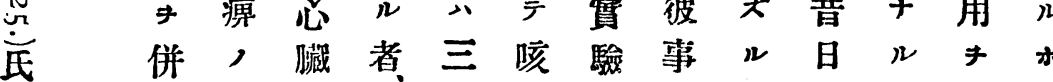
公發初病卒特嗽少實示, 专中+ 天゙ 女期代中間頻 ホト+重眠止 1 ル 卒償后中發未大1 木 助中機大 $=x \rightarrow=n=$ 催 十 間 等能 1 神 $=$ 障興瓦者 經於害舊 窒

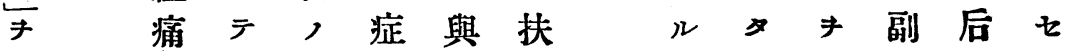

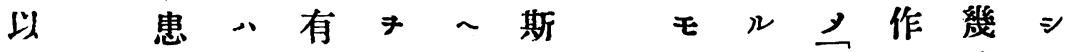
土 氣 一 管 名 $シ$ 問 \モ熹 枝 $\doteq \neq \leadsto n$ 無 期 粘於効 太者効 酒

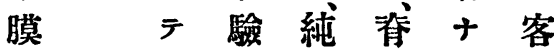
, 年用許 翌ル十モ 踓 夜木少十 $\pi^{*},+\eta \geqslant-$ 如睡 $1=\equiv$ 朝 ）眠 ルガテ重 


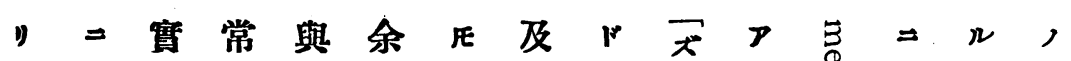

1 基驗 $\neq$ 二八尿

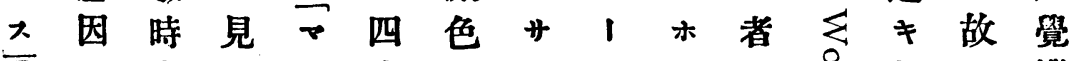

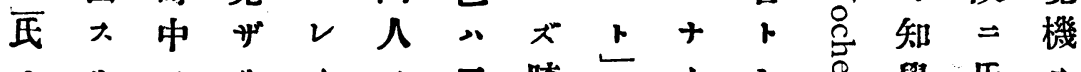

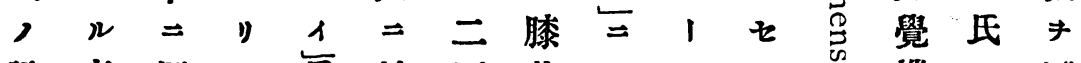

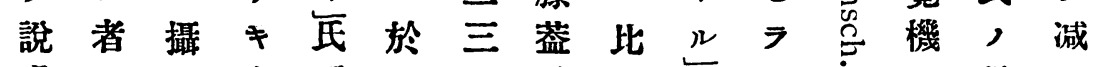
）取唯豚 $テ$ 回腱

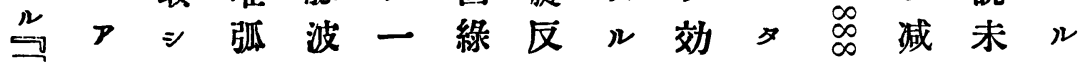

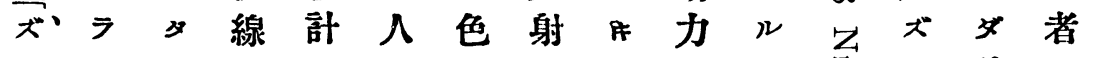
心ザ, *

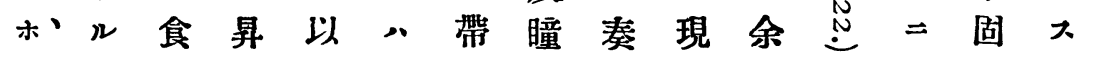
†フ事降テ四ビれ效”モ公足》ル 小或二敏瓦》反緩亦亦 心比“於年一心射慢、之ルザ者余

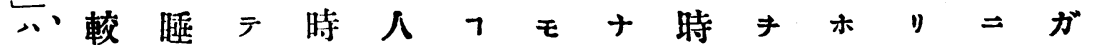
大試 眠八各 $=$ >亦》間確

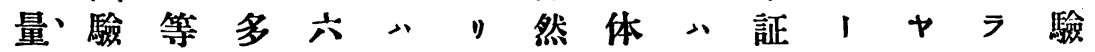
キ、 二 少時五キり温三シ片モ゙

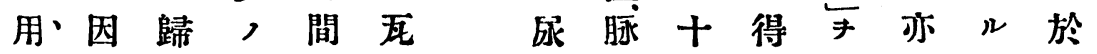

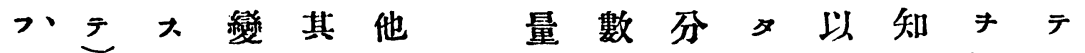
心知心化脉二亚妇》テル疑心

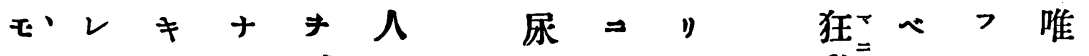

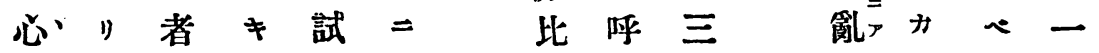
臟、故 $=$ = 驗、重吸時及 $7=$ 回

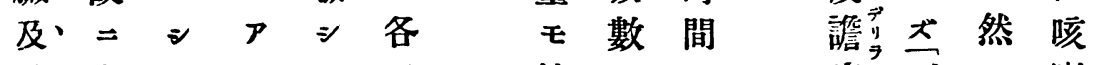

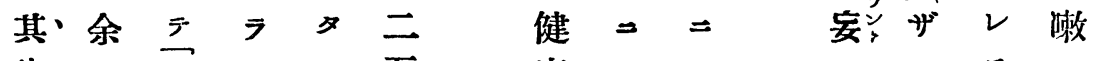
他、六 ザル无康ハア 八历ルリモ, 体記り對ゴ余制 血、大 $末 \Rightarrow$ 敢

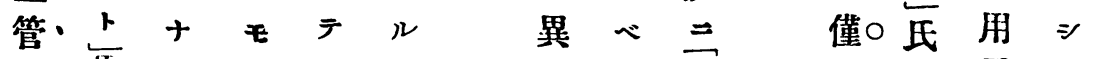

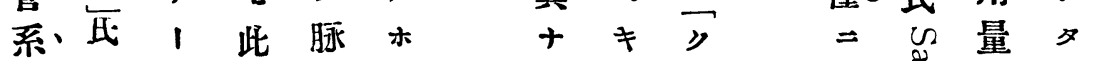
統、尽變弧+ + , 鎮 二、フ化線 1 ※゙影 作 用・用ル變年踓 靖竞劣 


\section{七O二號三十五第告報會究研事醫堂天順}

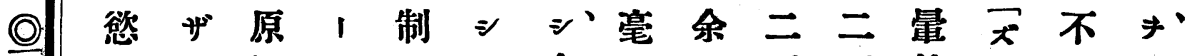
元 $\Rightarrow$ 因

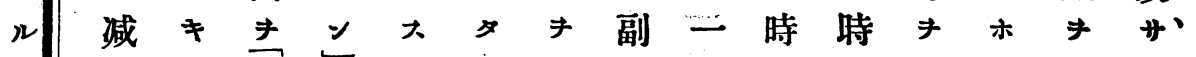
木 損唯 厎ル方作患間間將十目犬

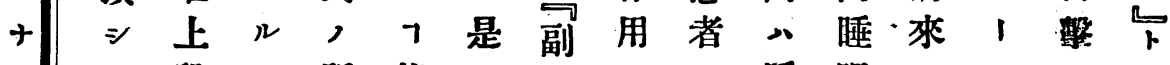
$1 \Rightarrow$ 段 水 所能 $十$ 作 + 二睡眠 $大$ 七, 几”

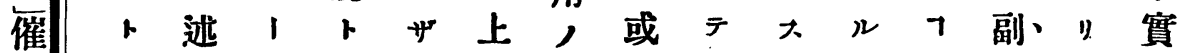

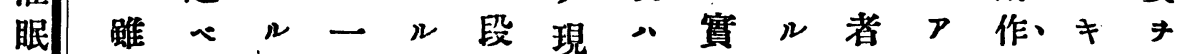

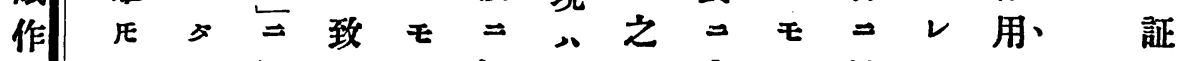
用亦ル歸 $ス$ 概既ル奇, 於氏川朋

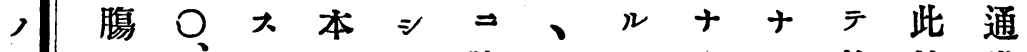
追 胃五へ品テ陳へモルり然等常 加 加 瓭 $\neq$ 服能大不極現 太 $\neq$ 用》ルルテ像 流與; 后之ガ 車 輕 等 $>+$ 嘔 二如 $+\neq$ 見 , 江》吐耐》，者》

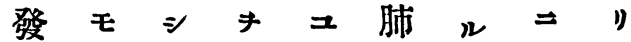
症重卜發儿瘦箠於即 $+\neq$ 踓 $三$ 者 患眠 $\bar{~}$ 力副氏 氐者ま偶、久 》作食ルり公强然特

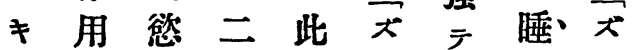
～及實點 ル中眠、 發消 見 $=$ 木絕 ま小 三化中付 t大破十

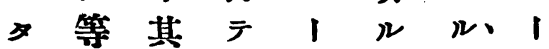

十 例敢 会点因症、紧 五 $\quad=$ 全, 由 2 㹜連 於變》實焉忽用 テた啹驗咳きない 八三吐上嫩疑 增川 食レ, 可 , 唯 7 現 疲 多 像 勞 》 八 倦 又一意 副日 作 F 殘 用 經 •ザ， 呈秋 大 $=$ 特 ル消 上 患 散 三 者大テ

$\Rightarrow$ 是耳 在 $レ$ 鳴

厂殊 頭 》 = 痛 大患劇 抵者 午翌, 前 朝 矓

三 得 タ ) 余 剩 ح 心 臟 病 $=$ 用

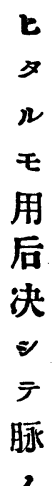


ま 氏 意 $ッ$ 因 ガ

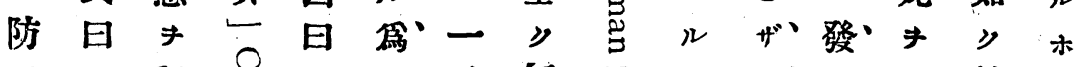

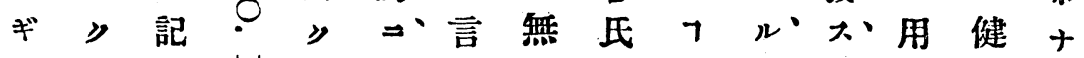
即催 $シ 00$ 。編催、大味, 一、ル、七康、

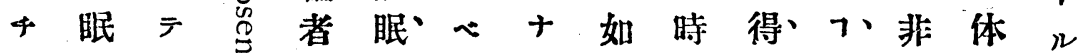

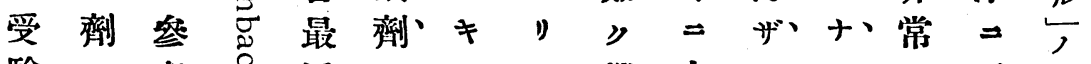
驗, 考仓近タ、心縱止り、キ、=五・副

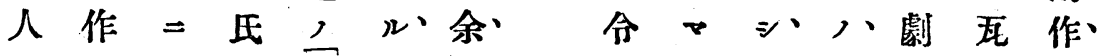

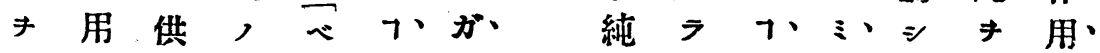

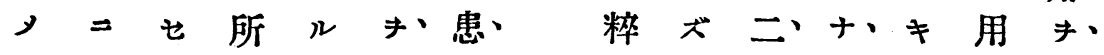
催就 一 說り知者、服回、ラ、副茾呈・ 眠 $\neq$ 二ン ラ、ニ、 劑正係病 シ、炅、 確ル床メンル、 服ナ睡週ザホ、 用ル 眠誌り・十、

F 批 知評 ラ シ $\rtimes \quad$ \# $\forall$ ン

ラ

ン 行

7 i

$\neq$ s

要 勉

フ. メ

故 テ

$=$ 精

余神

八)

催 動

眠 干
劑 ま シ 「、

試閱 オ、ル、

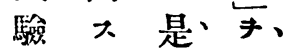
法ルナ、與、

, $=$ リ 注 ブ

意 レ

r $\rightarrow$

題 ラ

フ、尚

ル府

項

$>$ 口

1 1

今

其 У

大. ^r
2.

$\gg$ 、

勉。

メ、

テ、

精、

神、

作、

用、

キ。

像、

防、

そ、
ル 藥 ニ・ボ、作 テ

者 ま支却、用無

）止 ベテ、キ効キ、 用山り、久、呈十用。 フル余時、大り量、 ルモガ之、ルき モ唾實キ、フモ人 不眠驗連、ア他々 快 ノ催殆 カ、ガ一從

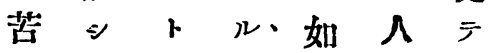
味得五件、シ = 一 > リ $\%$ 漸、, テ セ 卜本二な、實小大 大品於其、瞼其例 几, 者味 “量、徽分上 $>$ 小不 、、 レ 父眠至、无記 氏尚症ル、二即載

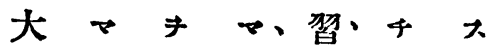
抵さ制 テ、慣、○、ル 


\section{九○二號三十五第告報會究㗞事醫堂天順}

H)

ル フ交五作量

上効 》》藥

小山眠用

キ 心量 的 催

事キ目試試

$+$

千 腚 缓

减 一

眠 他 水 賽

實 比的 驗 驗

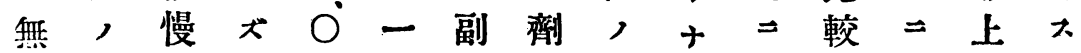

権 效原十

催 + 因片

夫定 作

以大用卓眠 $n \neq$ ト預 モ $=$

眠 リ若

作之 之 以

用 = 神 テ

ノ反 經之

迟 $三$ 痛

加 融二與

經 $>$

痛 ラル

$=サ^{*} ヤ$

於ル就

テカ 眠

八或 前

著 小-

効 咳 時

ま 嗽 間

收 頻 =

么 發 與

其 7

$=$ 因

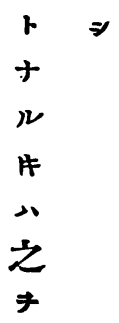

用

₹ 2

充 7 唯

分 能

且 入數的

※ 大

副宜

作 $\equiv$

用》》

+ 各而

キ人

量各モ

ト個重

大 其 カ

副 實 $\bar{~}$

作 驗 た

用 $=$

徽

發入

現

大

几 余

7 ,

$>$ 實

驗

\# =

八據

其 $x$
越藥 公余 $\neq=$ 精當

二其“艾丈神”

比作左與 患 作 受

フ者 用 噞

要 $\sim \neq \neq 1$

點 $三$ 催 及 $三$

無 確 二眠 ボ

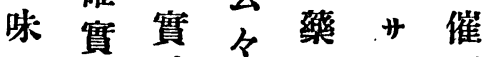

++ 噞

$n=\equiv$

舆 ル 藥

トザ 得

貴 ルヌ

要 モり

機 催

關 眠

二 樂

作

用 $=$

セ テ

将用

汸

$+2$

,

三 足

事 ル

他
$>$ 者

ルト ル

7 認 7

キ

告 知

グル

而人

几

後 撰 だ

千

催

眠 試 數

藥 驗 回

r $\neq$

催 行 試

眠 七 
二肺勞先七七十 七侯肺 至, , $\neq$, , 磪り夕勞 レ理重三ル解氏又ス八

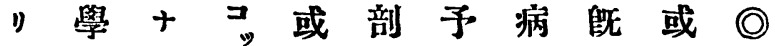
以的ルホ八中心理 $=ル$ 肺 前撿原氝結七只解病時勞 八索因, 締百八剖床期, 只, $\neq$ 結 織 入1家實 $=$ 預

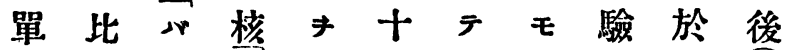
$=$ 較子小叭以 2 此家 $\bar{F}$

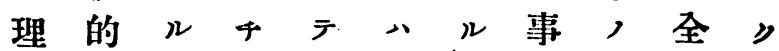
學尋大ル經偏式 的常下大界側, $三$ 知或为 撿 二確 索復定發畫大告益儿比 二大を見をな大確處較七

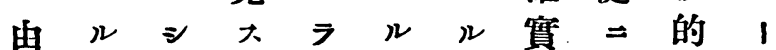
テ卜以ル上結所 $+三$ 治 之些來 $\forall \geqslant$ 核, $\bar{F}$ 喻

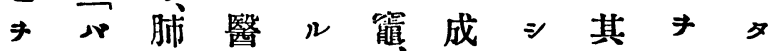
制 女勞學 結 六靕 厶 報得 定ル, 恎核百 $\neq$ 而告 $~ 1$

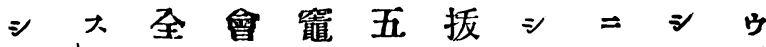
》癒, 几消、耳發七大之治云 , 失認目見”即二瘉入巡

：十定入七両子係七》 ） 悉り側一八敢 以可》, 万ル者戸 テキ之既六報, 論 必者 = 二千告多者 要 = 蝟㓔五數數, ・於集痕百多 喿 大 $テ=$ 六〉載々 ル 八肺結十りを
染笋他 苞 $=$ 詳 對 細 $=+$ 充 分 實

+ 驗 ル 錄 材 八 料 余 , ガ

給 卒

與 業

卜 論

等 交

切 =

+ 讓

" 1

補 茲

助 $=$

r 余

謝

大 1

(ㅅ

$\stackrel{9}{\Xi}$

庹

至 莫

矿4

$\stackrel{0}{:}$

$\begin{array}{ll}\infty & 4 \\ \infty & 4 \\ \infty & y\end{array}$ 